\title{
WHY DO COMPANIES USE FLEXIBLE FORMS OF EMPLOYMENT?
}

\author{
Simona Mrázováa ${ }^{301}$
}

https://doi.org/10.31410/itema.2018.837

\begin{abstract}
Every company wants to be profitable and have the best employees working for them. In order for a company to attract the best work force, they have to adapt themselves to current demands of labor market trends. There are many ways of attracting and motivating current and future employees such as providing various financial and non-financial benefits. One of the benefits is to provide flexible working environment for employees. Therefore, in era of advanced technologies, employees and job seekers are keener to work for an employer, who is willing to provide flexible forms of employment. Flexible forms of employment are understood as the ability of an employer to provide various forms of employment, such as: part-time work, telework / work from home, job rotation, etc. for his/her employees, without any restrictions. Not every employer is willing to provide such employment benefits for his/her workforce. For this reason, the aim of this paper was to show another point of view of the constantly changing demands within labor market. Due to providing the statistical data of the current market trends within the labor market, the predictions of the upcoming directions of the trends can be made. The purpose of this paper is to show what are the flexible forms of employment, what advantages and disadvantages do these forms bring along, and up to what extend do current employees use such forms of employment. The findings were supported by data, which were obtained from Eurostat, as well as by conducting empirical research method. There was also a survey distributed amongst 150 people, from which 33 were owners/managing directors of companies within EU countries, in order to obtain firsthand information. In conclusion, after conducting literature and market research, is shown that more people are willing to work for an employer, who provides non-financial benefit such as flexible forms of employment. It is also shown that the number of employers who provide this benefit constantly increases within EU countries.
\end{abstract}

Keywords: flexibility, forms of employment, labor market demand, employment

\section{INTRODUCTION}

$\mathrm{E}$ very company within each industry wants to be profitable. Technological advancements brought new ways and perspectives of approach to the ways of employment. Therefore, for a company in order to be able to attract the best employees and keep its current ones, it has to look for ways to meet the demands of the labor market conditions, as well as to keep up with the new technological advancements. The trend new technologies have brought up is that it tends to favor particular skills, while devaluing other ones redundant, but also lowering the demand for them by firms that use such new technologies [1].

Due to the broad use of technology, the digitalization has already impacted the demands of the labor market, but also it already has impacted the organization of work within companies. The companies started to evaluate how to organize their employees more efficiently, how to distribute the work more effectively, while increase their productivity and keeping their

${ }^{301}$ Comenius University in Bratislava, Faculty of Management, Odbojárov 10, P. O. BOX 95, Slovak Republic 
employees. One of the ways of the process for increasing the efficiency is to provide flexible forms of employment. Flexible forms of employment are considered to be a certain approach that a company is willing to undertake, in order to adjust itself against the constant market changes, modify its organizational structure, while creating flexible working positions. This way, the company itself will become flexible, with stronger bonds between the employees and the company, and will easier fight off market downturns. This means, the workplace flexibility will create the ability for workers to make their own choices influencing when, where, and for how long will they engage in work-related tasks [2].

The main goal of this article is to show what the new forms of employment are and to provide the advantages and disadvantages of it from the companies' and employees' point of view. This way, the readers will have better picture of forms of employment and could be a help when applying such forms of employment within their companies.

This article contains non-empirical research by completing literature analysis. Based on the analysis is completed empirical research method: survey and non-constructed interviews with owners/ managing directors of companies, from where are drawn out findings, showed on a graph. At last, there is a conclusion, where the major findings are discussed.

\section{LITERATURE ANALYSIS}

As mentioned in the introduction, in order for a company to easier resist possible market changes, the company has to adapt its organizational structure to offer greater number of flexible job arrangements. Creating such arrangements means to offer functional and/or numerical flexibility, while referring to John Atkinson, who was one of the first ones to define flexible organizations. There are three types of flexibilities which were brought up by J. Atkinson, but the most important are functional and numerical flexibility. He defined functional flexibility as possibility for employers to create such job positions, where employee is able to cope with different tasks, move between jobs, therefore having broader range of responsibilities. The advantage for the employer is the ability to easily change production methods and employee's workload without having a big influence on the company's ongoing operation. The numerical flexibility is considered as the ability of a company to adjust the number of employees or their working hours to the company's needs [3].

In regard to above mentioned flexible organizations, law makers of countries worldwide started to pay closer attention to flexible working arrangements and to put exact boundaries for the definition of flexible forms of employment. In Europe, based on the study of European parliament published in 2007, were defined six terms of flexible contractual arrangements:

- several forms of fixed-term and temporary employment contracts

- part-time employment contracts, (including mini-jobs, on-call work and job sharing)

- home working and telework

- flexible forms of working time

- occasional work contracts

- civil law contracts [4]

Fixed-term and temporary employment contracts are forms of employment, where the company hires an employee for a specific time period, and can be renewed after its expiration, depending on the company's needs [5]. These forms of employment take place in cases when a company needs to hire a person for a particular purpose; in many cases it is when a company needs an expert within a certain field in order to complete a project, where it is known how much time 
the project will take place. Furthermore, would be when a future of a company is uncertain, such as start-ups, and the management decides to hire employees for a given time period, to see whether the company will be successful or not. Other case is a seasonal work, especially in area of agriculture, where during certain seasons the workload increases, and the need of employees is necessary.

When it comes to part-time employment, this form of employment has many advantages for both employees and the employer. In many cases, when an employee wants to take care of the family, to study besides work, have other job or wants to have more time for other activities, they choose to work part-time. Part-time doesn't necessarily mean the employee has to come to work every day and work half the time regular employee works. It is up to the agreement between both sides: employee and employer to agree on conditions, and to find the compromise. In many cases companies agree to offer such forms of employment, so they offer more freedom to their employees but also get to keep them in their company. Another reason why companies choose such form of employment is called job-sharing. It is when for one position they rather hire two people, instead of hiring just one person. Even though, the costs of the labor for company might increase, depending on the legislature of a country, sometimes the task is better done when it is being completed by two people, working at different times rather than one person completing the task. Mini/midi jobs are part-time jobs, that were first used in Germany in 2003, which conditions are that when a person has a mini/midi job he/she can earn maximum certain amount in order to be qualified for such job, depending on the minimum wage of the country [6].

According to legislature of Slovakia, home working is home working defined as a form of work, where a person is able to work from home or other place agreed on with the employer, while not having the need of any type of ICT [7]. This is applicable for jobs such as crafting, handmade production, etc.

Telework on the other hand is in the Slovak legislature defined as work, where a person can work from home, while having the ability to use ICT [7]. This type of work is in nowadays era broadly used, because companies as well as employees are aware of the positives this form of employment offers. When a person works by telework, he/she is not tight to any specific place, nor strictly tight to a schedule. From company's point of view, the positives are that the company doesn't have to have additional expenses for office rent, the employee can spend more time with the client, manage his/her time according to his/her needs, and this increases the attractiveness of the job position and the company becomes more demanded within the labor market. From the employee's point of view, the positives are self-time management, ability to choose environment that suits the best his/her needs, while having enough time to spend time with the family or by having hobbies besides work. This way, it is easier for an employee to create his/her work-life balance.

However, there are also some downsizes to telework. The major barrier which might appear is the company might decline the frequency of communication with the employee. In such form of employment, frequent communication with the employee is essential [8]. When a company loses the frequency of the communication, it might lead to employee feeling left out from the company's social functions, foremost to social isolation.

Flexible forms of working time are form of employment, where the employee decides on weekly /monthly basis with the employer the time when the employee will be present at work. Just as it was with telework, this form of work has some advantages and disadvantages. The major 
challenge employee might have to face is the times employer wants the employee to be present at work. The times might not always be suitable for the employee, but it is up to both sides to come up with a compromise. The reasoning behind the implementation of flexible forms of working time could be presented by employers as a condition for making positive decisions on employment within the company. Example could be caused that the company is losing its profitability and there might be some job losses, guaranteeing that existing employment levels will be maintained for a certain period, or making commitments on job creation [9]. Again, flexible forms of working time creates an opportunity for an employee to negotiate his/her working hours which would be in favor of the work-life balance, and/or for the employer to keep their employees even if the economic situation of the company is not positive at that given moment, and this way it would be beneficiary for both sides.

A form of work arrangement that is mainly beneficiary for the employer is an occasional work contract. In such case, the company hires a worker on occasion, for a stated time period. It depends on the company's demands for workforce during periods of times when needed.

Last form of employment to be mentioned is the civil law contracts. Civil law contracts are commonly used when the employer does not plan to employ a worker under an employment contract, but requires the performance of certain activities or for some specified work to be completed [10].

\section{SURVEY OBJECTIVE AND METHODOLOGY}

The aim of this study research was to determine the reasons of why companies nowadays use flexible forms of employment and what impacts does it have on the companies and employees as well. After conducting literature review, where the aim was to study and provide information and types of forms of employment that are at the current labor market, written by authors, who studied and/or are experts of the topic of this paper.

Based on the knowledge gained from the literature analysis, was conducted empirical research method by obtaining relevant data from Eurostat and by constructing questionnaire. The questionnaire was anonymous, and was distributed electronically, via Google forms to 150 employees and 33 owners/ managing directors of companies within EU region. Besides the questionnaires, there were conducted unstructured interviews with some of the owners/ managing directors, in order to get more insights of the topic studied.

\section{RESULTS}

Prior to the distribution of the questionnaire, the first step to be done was to look for statistical data available online, and to see into what extend within the EU region and Slovakia, companies use flexible forms of employment. To see whether people are willing to work various working hours, what might be the reasons for their decision, and if available, what kind of flexible forms of employment are there. After the research, the platform with most reliable data available is Eurostat. However, the data online regarding to flexible forms of employment are limited, therefore as a basic step was to find how many people work full-time and how many people work part-time, since part time is one of the flexible forms of employment. On the two graphs below are compared numbers of employees (in thousands) who work part time with ones who work full-time with EU region and in Slovakia since 2007. In both cases is shown that the number of people who work part-time increased throughout the time, but on the other hand, this doesn't apply to full-time employment. On these two graphs are shown how did the EU economic crisis influenced full-time employment within the regions, and also shows the 
correlation of economic status of a region with employment. Other forms of employment were not found, which might be due to a fact that it is up to the employer himself to decide whether they are willing to offer other flexible forms of employment or not.

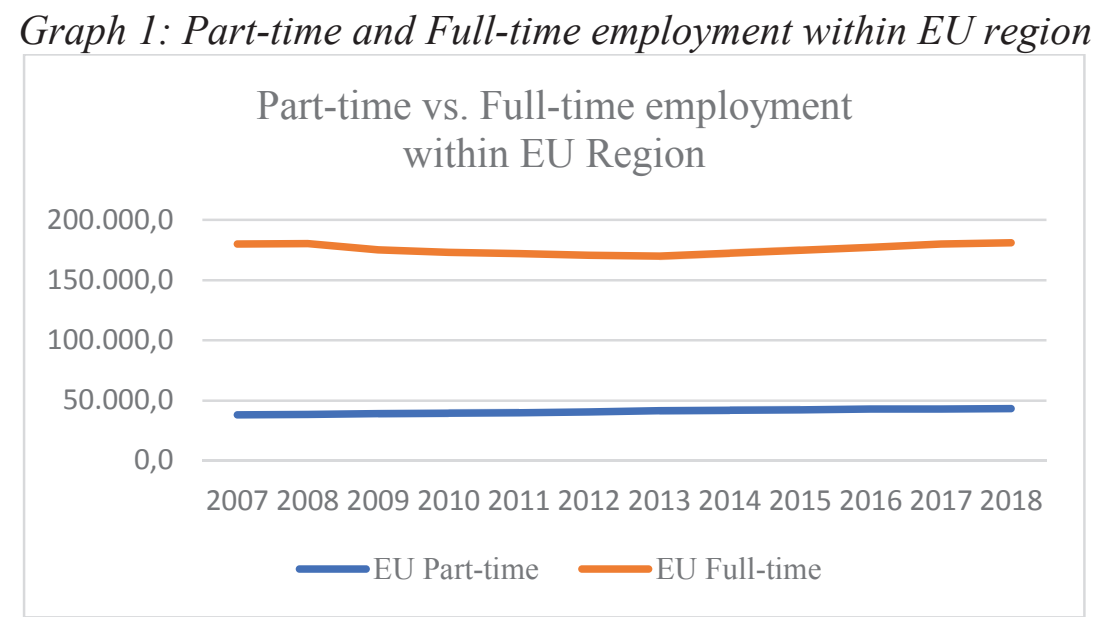

Source: http://appsso.eurostat.ec.europa.eu/nui/show.do

Graph 2: Part-time and Full-time employment in Slovakia

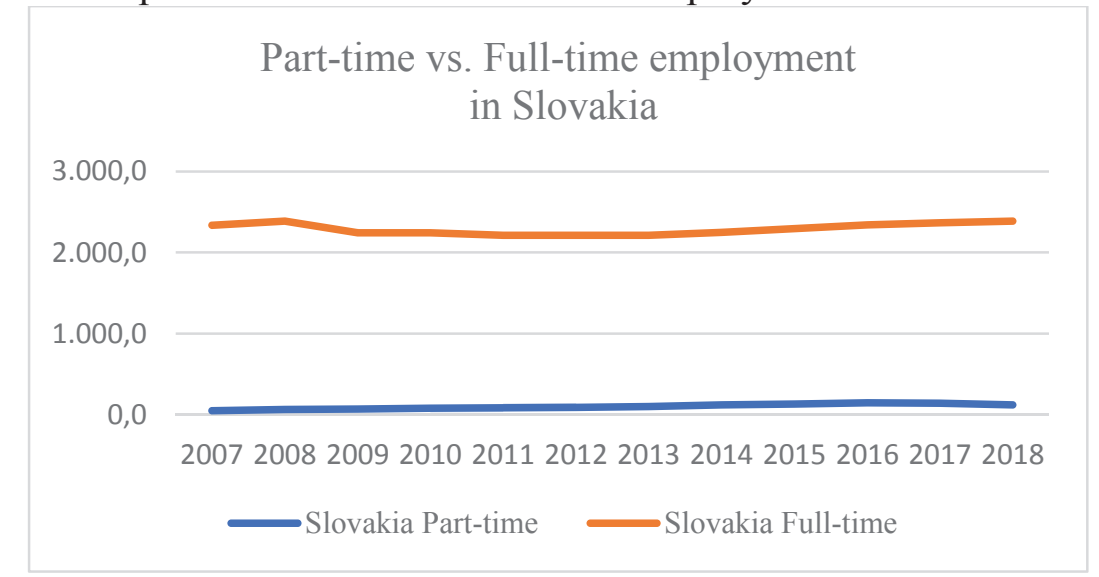

Source: http://appsso.eurostat.ec.europa.eu/nui/show.do

After the online and literature research was done, the construction and the distribution of the questionnaire were followed. The questionnaire was distributed to HR departments of companies, who offer flexible forms of employment, via Google forms, which was later on completed by their employees, including the owners/ managing directors. Since in completing an online questionnaire could be time consuming, the structure of this questionnaire was very simple; people had to answer "Yes" or "No" and only if they wanted to share some of their experiences, for every question there was a place for them to share it. The first question asked was whether they think flexible forms of employment bring along more advantages than disadvantages. 100 percent of the employees, as well as the employers agreed there are definitely more advantages. Then the questions were constructed as "In your opinion, do you think flexible forms of employment enhances ... (terms provided within the graph) ...? Please, explain your answer." The last part of the questionnaire there was a blank space for them to share their opinion/experiences with flexible forms of employment. Later on, there were carried unstructured interviews with some of the owners/ managing directors of the companies, by where more details and disadvantages of such forms of employment were obtained. (Results of the interviews are shown in graph no. 4 below) 
Advantages

In the graph no.3 bellow are shown results of the questionnaire distributed to the employees and owners/ managing directors of companies (the higher the percentage, the more people agreed flexible forms of employment support given area- task). The blue colors are shown percentage values of employees and the orange color are shown values of the answers obtained from the owners/ managing directors of companies.

\section{Graph 3: Results of the questionnaire}

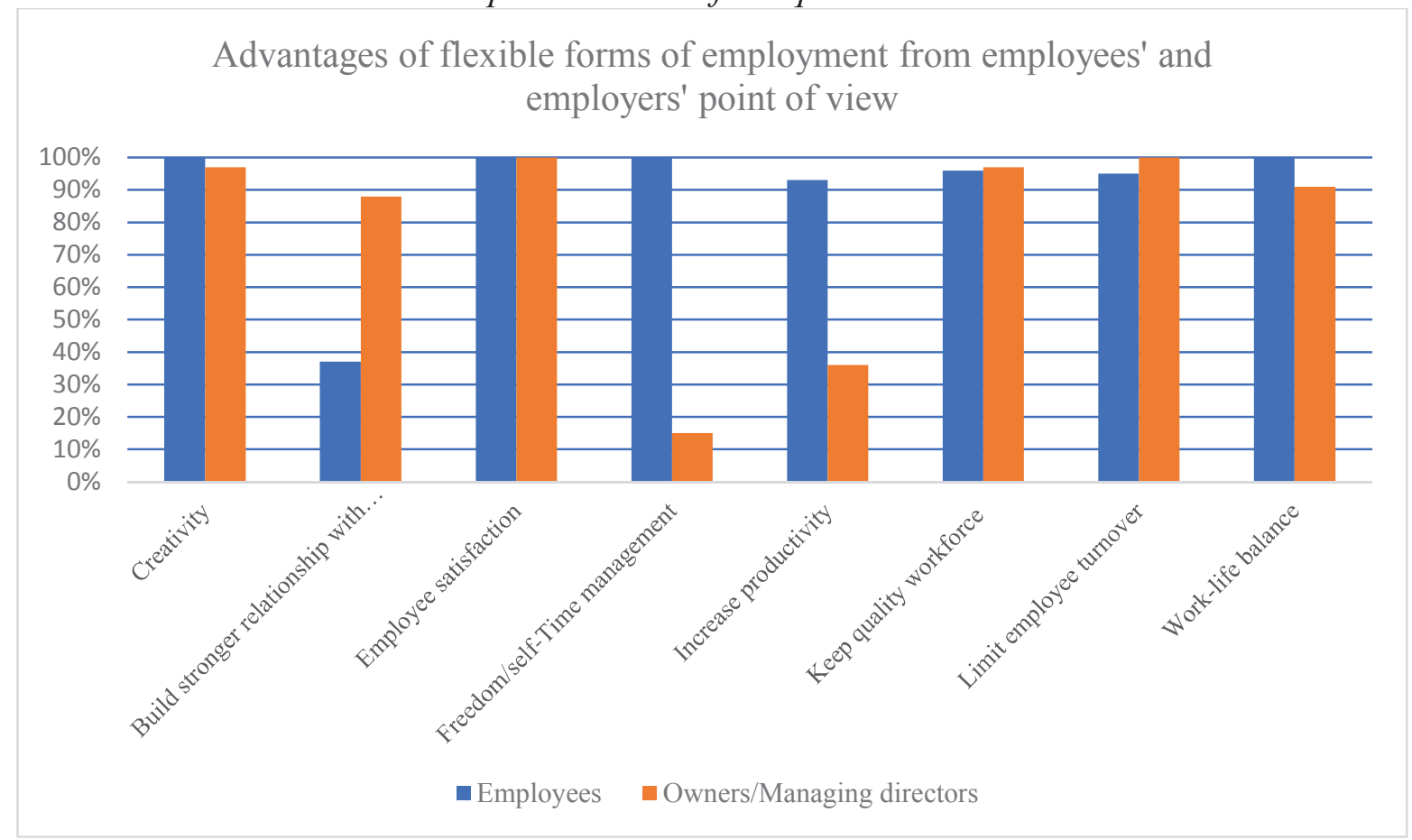

Source: own elaboration constructed from the result of the questionnaire

As shown, most of the terms received similar answer from both groups asked. Since employees are not strictly tight to a certain work place nor schedule, but know what needs to be done from them, the high level of employee satisfaction is a result of flexible work arrangement and is one of the major advantages this type of employment brings along. Employee satisfaction is then linked with keeping the quality workforce and limiting the employee turnover. In many cases the process of hiring someone is time-consuming, and training process is expensive. According to the Association for Talent Development, the cost of training and development of new employees in 2016 in the USA cost on average 1,252 USD per employee [11]. To avoid employee turnover and costs that come along with the hiring and training, employee satisfaction decreases employee turnover and also provides such conditions, that companies get to keep its employees, including the key ones. On the other hand, having such incentives such as ability to work from home when a member of the family is sick, having flexible work schedule so people can devote themselves to their families or hobbies, is an incredible advantage, which people are aware of. This way there is a smaller chance people would be willing to change jobs and work for an employer, who isn't so lenient towards his/her employees.

Due to flexible work arrangements, employees are not tight to work only at the office, so they can work in such environment, which supports their creativity and can free out their imagination. This is important when a person has a job, where creativity is necessary for their job tasks. When an owner of marketing company was asked why he doesn't ask his employees 
to work from $9 \mathrm{am}$. to $5 \mathrm{pm}$. only within the premises of the company, the response was quite simple "the success of my company from a main part depends on the creativity of my employees" [12]. Since people who work in marketing, fashion, art or other type of similar business where they have to be creative, they also have to make sure they have working conditions which supports their creativity can be more productive as well as satisfied with the quality of their work. Another factor which comes along by not having a strict work schedule is work-life balance. When people besides their work have enough time to take care freely of their families or themselves by educating, training, or having other out-of-office activities, their mental health improves and can easier balance their work and life. Work-life balance influences not only productivity of the employee, but also his/her relationships within the work place, as well as health [13].

The other three terms had different points of views. Only 33 percent of employees thought flexible forms of employment help to build a stronger relationship with the customer, where 88 percent of owners/ managing directors agreed with this. Being more flexible and available for the customer is important aspect when keeping the customer. For this reason, owners believed this is an advantage that flexible work arrangement brings along. An owner of a hotel chain said: "There are many hotels customers can choose from, but why do you think they choose us? Not only because of the hotel itself, but also from the first moment, they stay in contact with the same person, who responds to them even during the weekend. Personalized service is what makes us different."[12]

Interesting was finding that owners/managing directors didn't believe flexible forms of employment increase productivity of employees. Only 36 percent thought this work arrangement increases productivity, while the other ones thought it is actually a disadvantage, by reasoning once a person works remotely, he/she doesn't feel the pressure and only gets done what is needed from him/her and doesn't proactively ask for more tasks. There is an unconscious behavior of out of sight, out of mind. On the graph 4, which is shown below, managers decided productivity should be placed in the disadvantage part (note: 64 percent of managers believe the productivity of employees working remotely decreases, in comparison if they work from the office), where employees believed their productivity was more efficient but also done at a higher quality. Important is also a finding, that the 36 percent, who think the productivity of employees increases while working remotely, have a creative business such as advertising agency, marketing company, etc. In this case, it depends on from which point of view a person looks at the issue.

The last term within the advantages section is self-time management. Just as it was with productivity, the opinions about self-time management were diametrically opposed. Where 100 percent of employees agreed it is an advantage not only for the employees but also for the company itself, only 15 percent of the owners/managing directors believed it could be advantage for the company. Employees like the fact they can do their job on a flexible basis, wherever they choose to do so and also believed their time management is efficient enough for the company. On the other hand, employers didn't believe so. They believe not being in the office and not feeling the work atmosphere; employees become idler and might not effectively manage their time to coordinate their work responsibilities with other responsibilities. Also, when a person knows the deadlines for his/her tasks, it is frequent they finish it at the last moments within the deadline, because there are more distractions when working outside of office. 


\section{Disadvantages}

Since there are many advantages that come along the flexible work arrangements, there are also some disadvantages which were brought up by the owners/managing directors and are shown in the graph no 4 . below.

Graph 4: Results of the questionnaire

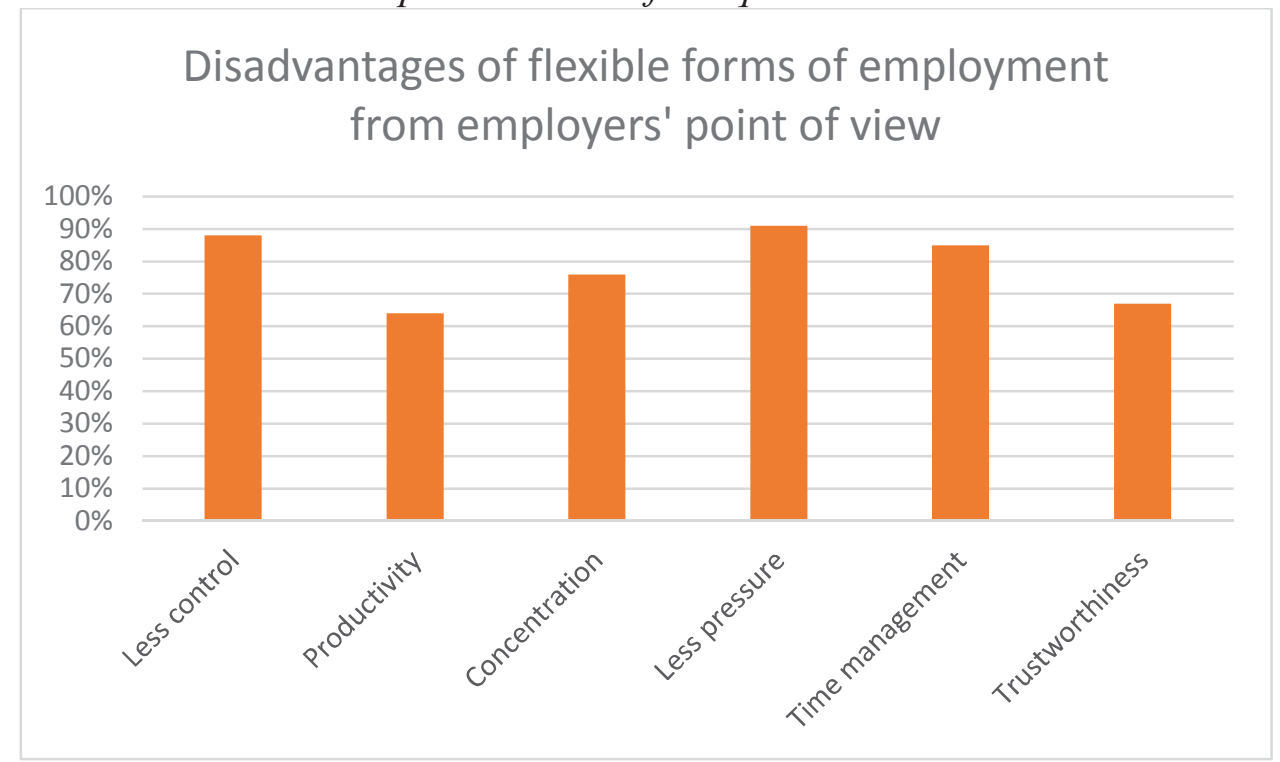

Source: own elaboration constructed from the result of the questionnaire

After productivity, where 64 percent, believed might decrease while having flexible forms of employment, the second aspect with less percentage -67 was trustworthiness. Trustworthiness is closely linked with less control. Owners/managing directors sometimes suspect that their employees not all the time work the hours they report, which is caused by management having less control of their work activity. Example obtained from the unstructured interview was with an owner of a company, who employs number of sale representatives, who travel across the country and sell the company's products. These people have set up weekly goals they have to meet, and the owner believes that if in one day they meet the goals, for the rest of the working week they pretend they work. On the other hand, he doesn't want to put pressure on them by closely controlling them, because they do their job, meet their goals and is afraid they would want to leave the company.

By being under less pressure and work outside of the office, there is a tendency of people losing their concentration on the work tasks and concentrate more on non-work-related activities. As mentioned previously, people tend to get distracted easily. For this reason, advantage of less pressure in employee's point of view is disadvantage for the employer's, by putting less pressure on the employee's output.

\section{CONCLUSION}

The aim of this paper was to research and analyze the reasons why do companies use flexible forms of employment. As a first step, was used non-empirical research by conducting literature review and analysis. In the literature analysis were provided and explained forms of employment that are offered by companies within European labor market. Based on the findings, was constructed an online questionnaire which was distributed to 150 employees and 
to 33 owners/ managing directors of companies, and later on with some of them was conducted an unstructured interview, in order to get more insights why these employers offer such forms of employment. The results are shown and described in the result part.

The findings from the results brought new aspects and insights than just the literature analysis. From the results it is clear that employees have diametrically opposite points of views about advantages and disadvantages of flexible forms of employment, in comparison to their employers. However, there was some congruency between their points of views. During the unstructured interviews it was very clear the employers are aware of the importance to offer the best working conditions which suits their employees, especially to create working environment, which would increase their productivity and quality of their work. Therefore, the companies constantly look for way to create such conditions, including coming up with the best form of employment for them, and not hurting the company.

Nowadays, the labor market is more competitive, and companies must do its best in order to acquire the best workforce available. For this reason, employers look for various ways to attract their future employees as well as to keep their current ones. People's priorities had shifted, and it usually happens that they choose an employer who offers them various incentives such as non-financial benefits, but mostly options of flexible work arrangements. This way the employees get to manage their time accordingly to their wants and needs, including creating their own work-life balance. According to the research for this article, flexible work arrangements have its advantages but also disadvantages. It is however up to the employer to reconsider what kinds of flexible forms of employment is he/ she willing to offer for his/ her employees, and which ones would be the most efficient for the company as well as for the employees.

\section{REFERENCES}

[1] Dachs, B. (February 2018). The impact of new technologies. [Online] Available: European Parliament:

http://www.europarl.europa.eu/RegData/etudes/STUD/2018/614539/EPRS_STU(2018)6 14539 EN.pdf

[2] Hill et al. (May 2008). Defining and Conceptualizing Workplace Flexibility. Community Work \& Family (Community Work Fam), s. 149-163.

[3] Atkinson, J. (1984). Manpower Strategies for Flexible Organizations. London: Personnel Management.

[4] Parliament, E. (June 2007). The impact of new forms of labour on. [Online] Available: European http://www.europarl.europa.eu/RegData/etudes/etudes/join/2008/408574/IPOLEMPL_ET(2008)408574_EN.pdf

[5] Times, T. E. (2018). The Economic Times. [Online] Available: https:/economictimes.indiatimes.com/definition/fixed-term-employment

[6] Blankenburg, S. (21. August 2012). The Guardian. [Online] Available: 'Mini-jobs' don't work in Germany, and they won't work in Britain: https://www.theguardian.com/commentisfree/2012/aug/21/mini-jobs-germany-britain

[7] Slovakia, L. C. (2001). Collection of Labor Code of Slovakia. [Online] Available: http://www.sczsk.sk/legislativa/z\%C3\%A1kon\%20311-2001.pdf

[8] Wojcak, E. (2013). Flexible forms of work organization. Bratislava: Of print s r. o. Management. 
[9] Freyssinet, J. (27. May 1998). Flexibility of working time in Europe. [Online] Available: Eurofound: https://www.eurofound.europa.eu/publications/report/1998/flexibility-ofworking-time-in-europe

[10] Info, M. (2017). Migrant info.pl. [Online] Available: Civil Law Contracts: http://www.migrant.info.pl/Civil_law_contracts.html

[11] Development, A. f. (8. December 2016). ATD Releases 2016 State of the Industry Report. [Online] Available: Association for Training Development: https://www.td.org/insights/atd-releases-2016-state-of-the-industry-report

[12] Unstructured interviews conducted in May, 2018

[13] Lockwood, N. R. (2003). Work/Life Balance Challenges and Solutions. Society for Human Resource Management. 